\title{
PENYIRAMAN TANAMAN SECARA OTOMATIS MENGGUNAKAN SENSOR SUHU DAN KELEMBABAN BERBASIS MICROCONTROLER
}

\author{
Surianto Sitepu \\ Dosen Fakultas Ilmu Komputer Universitas Methodist Indonesia \\ surintositepu69@gmail.com
}

\section{ABSTRACT}

\begin{abstract}
Has designed a tool that serves to maintain the plant to grow well. Plants that grow well in need of treatment were quite good, especially in maintaining soil moisture. So that the land remains under inert conditions in accordance with the standard requirements necessary plants enough water. For that need attention regularly for watering plants. Automatic Plant Watering prototype uses temperature sensors and inertialbased Microcontroller Arduino Uno can be used in the treatment plant without the need to set watering schedules. In order for watering is not carried out during the day or during the scorching sun, the temperature sensor is used. Arduino microcontroller pin which has 14 digital input / output, which serves as the center of the brain process or the automatic sprinklers. The system was designed using a motor driver to drive the motor to pump water watering. Watering can prototype uses temperature sensors and inertialbased microcontroller arduino uno to move in automation tools for soil moisture has not been reached. If the soil moisture has been reached then the pump will stop watering the plants.
\end{abstract}

Keywords: Microcontroller, air temperature, soil moisture.

\section{PENDAHULUAN}

Dengan adanya program Pemerintah untuk penghijaun Go Green di hutan Indonesia, maka di harapkan masyarakat juga dapat ikut serta dalam mewujudkan program Pemerintah, dengan cara menanam tumbuhan sendiri di rumah baik tanaman hias maupun tanaman yang menghasilkan buah. Sedangkan untuk merawat tanaman tidaklah semudah yang dibayangkan dimana dibutuhkan keterampilan, ketelatenan, waktu dan biaya yang memadai agar tumbuhan dapat bertumbuh dengan baik. Seiring dengan kemajuan teknologi dibidang elektronika dan digital seperti komponen, microcontroller mengalami perkembangan yang sangat cepat, penggunaan yang mudah, fungsi yang kompleks sangat membantu untuk perancangan system secara otomatis. Untuk mendeteksi keadaan banyak komponen yang dapat digunakan salah satu adalah sensor. Sensor digunakan untuk mendeteksi kelembaban tanah disekitar tanaman. Mikrokontroller dapat digunakan sebagai pusat pengendali yang menerima masukan dari sensor. Komponen komponen tersebut dapat diterapkan untuk mengatasi permasalahan tersebut karena beberapa jenis sensor yang digunakan dapat mendeteksi tingkat kelembaban serta suhu di sekitar tanah tanaman sekaligus tingkat kelembaban di dalam tanah tanaman, dalam hal ini diharapkan dapat mempermudah dalam perawatan tanaman. Penelitian ini bertujuan untuk merancang alat penyiram tanaman otomatis menggunakan sensor kelembaban berbasis microcontroler ATMega 328, dan mengimplementasikan cara kerja sensor kelembaban pada Microcontroler ATMega 328. Manfaat yang ingin dicapai dari penelitian untuk dapat membantu pekerjaan manusia dalam menyiram tanaman dan Efisiensi waktu dan biaya dalam perawatan tanaman.

\section{TIJAUAN PUSTAKA \\ Microcontroller}

Microcontroller merupakan sebuah prosesor yang digunakan khusus untuk kepentingan pengontrolan, meskipun mempunyai bentuk lebih kecil dari komputer pribadi dan mainframe, microcontroller dibangun dengan elemen-elemen yang sama. Microcontroller adalah alat yang mengerjakan instruksi-instruksi yang diberikan, artinya bagian utama dari suatu sistem otomatis/terkomputerisasi adalah program di dalamnya yang dibuat oleh programmer. Program menginstruksikan microcontroller untuk melakukan jalinan yang panjang dari aksi-aksi sederhana untuk melakukan tugas yang lebih kompleks sesuai keinginan 
programmer. Pada Microcontroller perbandingan antara RAM dan ROM-nya besar, sedangkan pada sistem komputer juga besar. Microcontroller merupakan sebuah chip yang dapat menyimpan program yang fungsinya sebagi pengontrol rangkaian elektronik. Berbeda dengan mikroprosesor yang merupakan Central Processing Unit (CPU) dimana memori dan I/O pendukung komputer terpisah, pada microcontroller memori dan $\mathrm{I} / \mathrm{O}$ pendukung lainya terkemas dalam sebuah chip tersebut, Sehingga kelebihan utama microcontroller menjadi sangat ringkas. Microcontroller jenis MCS51 sudah mencapai 25 tahun, jenis microcontroller ini pertama kali dikembangkan pada tahun 70-an oleh Intel Coorporatioan. Microcontroller MCS51 merupakan keluarga yang masih banyak dikembang oleh produsen seperti Atmel corps, Philips Semicunduktors, Cygnal Intergrated product inc dan Winbond Elektronics Corp. Microcontroller jenis MCS51 terdiri dari beberapa tipe diantaranya AT89LS53, AT89S51, AT89S53 dan AT89S8252 dan salah satu yang banyak digunakan pada saat ini adalah jenis ATMega 328, pada pembuatan alat ini microcontroller yang akan digunakan adalah microcontroller ATMega 328, (Sudrajat Asep, 2005:3).

\section{ATMega 328}

ATMega 328 adalah microcontroller keluaran dari atmel yang mempunyai arsitektur RISC (Reduce Instruction Set Computer) yang dimana setiap proses eksekusi data lebih cepat dari pada arsitektur CISC (Completed Instruction Set Computer).

Microcontroller ATMega 328 memiliki arsitektur Harvard, yaitu memisahkan memori untuk kode program dan memori untuk data sehingga dapat memaksimalkan kerja dan parallelism. Instruksi instruksi dalam memori program dieksekusi dalam satu alur tunggal, dimana pada saat satu instruksi dikerjakan instruksi berikutnya sudah diambil dari memori program. Konsep inilah yang memungkinkan instruksi - instruksi dapat dieksekusi dalam setiap satu siklus clock. 32 x 8-bit register serba guna digunakan untuk mendukung operasi pada ALU ( Arithmatic Logic unit) yang dapat dilakukan dalam satu siklus.

\section{Konfigurasi PIN ATMega 328}

ATMega 328 memiliki 28 pin, yang masing-masing pin nya memiliki fungsi yang berbeda-beda baik sebagai port maupun fungsi yang lainnya. Gambar 1 merupakan deskripsi Pin Mikrokontroller.

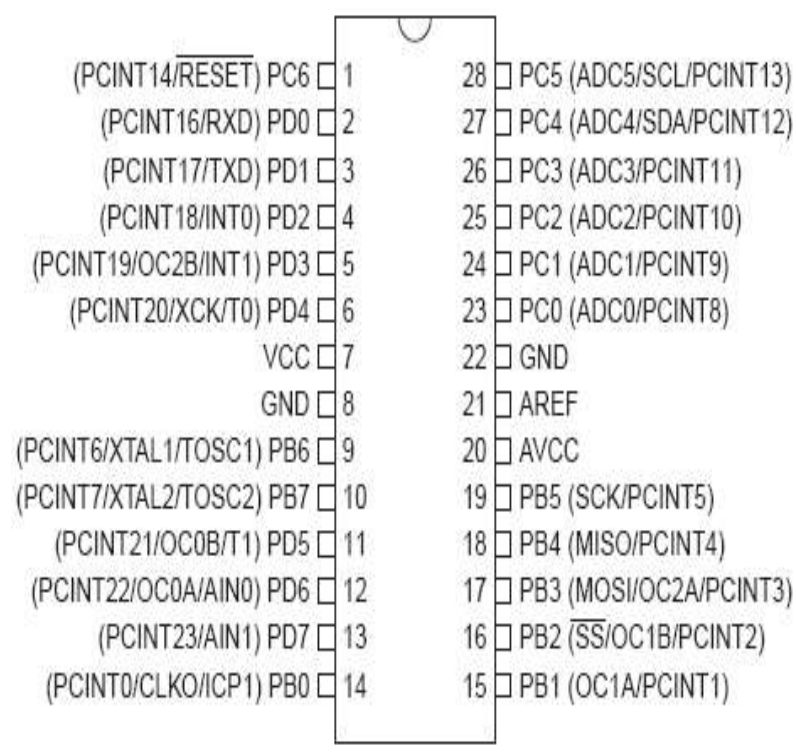

Gambar 1 Konfigurasi Pin ATMega 328

Fungsi dari masing-masing kaki ATMega 328.

1. VCC

Merupakan supply tegangan digital.

2. GND

Merupakan ground untuk semua komponen yang membutuhkan grounding.

3. Port B (PB7...PB0)

Didalam Port B terdapat XTAL1, XTAL2, TOSC1, TOSC2. Jumlah port B adalah 8 buah pin, mulai dari pin B.0 sampai dengan B.7. Tiap pin dapat digunakan sebagai input maupun output. Port B merupakan sebuah 8-bit bi-directional I/O dengan internal pull-up resistor. Sebagai input, pin-pin yang terdapat pada port B yang secara eksternal diturunkan, maka akan mengeluarkan arus jika pullup resistor diaktifkan. Khusus PB6 dapat digunakan sebagai input kristal (inverting oscillator amplifier) dan input kerangkaian clock internal, bergantung pada pengaturan Fuse bit yang digunakan untuk 
memilih sumber clock. Sedangkan untuk PB7 dapat digunakan sebagai output kristal (output oscillator amplifier) bergantung pada pengaturan Fuse bit yang digunakan untuk memilih sumber clock. Jika sumber clock yang dipilih dari oscillator internal, PB7 dan PB6 dapat digunakan sebagai I/O atau jika menggunakan Asyncronous Timer/Counter 2 maka PB6 dan PB7 (TOSC2 dan TOSC1) digunakan untuk saluran input timer.

4. Port C (PC5 ...PC0)

Port $\mathrm{C}$ merupakan sebuah 7-bit bi-directional I/O port yang di dalam masing- masing pin terdapat pull-up resistor. Jumlah pin nya hanya 7 buah mulai dari pin C.0 sampai dengan pin C.6. Sebagai keluaran/output port $\mathrm{C}$ memiliki karakteristik yang sama dalam hal menyerap arus (sink) ataupun mengeluarkan arus (source).

\section{RESET/PC6}

Jika RSTDISBL Fuse diprogram, maka PC6 akan berfungsi sebagai pin I/O. Pin ini memiliki karakteristik yang berbeda dengan pin-pin yang terdapat pada port C lainnya. Namun jika RSTDISBL Fuse tidak diprogram, maka pin ini akan berfungsi sebagai input reset. Dan jika level tegangan yang masuk ke pin ini rendah dan pulsa yang ada lebih pendek dari pulsa minimum, maka akan menghasilkan suatu kondisi reset meskipun clock-nya tidak bekerja.

6. Port D (PD7 ...PD0)

Port D merupakan 8-bit bi-directional I/O dengan internal pull-up resistor. Fungsi dari port ini sama dengan port-port yang lain. Hanya saja pada port ini tidak terdapat kegunaan-kegunaan yang lain. Pada port ini hanya berfungsi sebagai masukan dan keluaran saja atau biasa disebut dengan I/O.

7. Avcc

Pin ini berfungsi sebagai supply tegangan untuk ADC. Untuk pin ini harus dihubungkan secara terpisah dengan VCC karena pin ini digunakan untuk analog saja. Bahkan jika ADC pada AVR tidak digunakan tetap saja disarankan untuk menghubungkannya secara terpisah dengan VCC. Jika ADC digunakan, maka AVcc harus dihubungkan ke VCC melalui low pass filter.

8. ARef

Merupakan pin referensi jika menggunakan ADC.

\section{Arduino}

Arduino didefinisikan sebagai sebuah platform elektronik yang open source, berbasis pada software dan hardware yang fleksibel dan mudah digunakan yang ditujukan untuk seniman, desainer, hobbies dan setiap orang yang tertarik dalam membuat objek atau lingkungan yang interaktif. Arduino sebagai sebuah platform komputasi fisik (Physical Computing) yang open source pada board input ouput sederhana, yang dimaksud dengan platform komputasi fisik disini adalah sebuah sistem fisik yang interaktif dengan penggunaan software dan hardware yang dapat mendeteksi dan merespons situasi dan kondisi.

Kelebihan arduino dari platform hardware microcontroller lain adalah:

1. IDE Arduino merupakan multiplatform, yang dapat dijalankan di berbagai sistem operasi, seperti Windows, Macintosh dan Linux.

2. IDE arduino dibuat berdasarkan pada IDE Processing, yang sederhana sehingga mudah digunakan.

3. Pemrograman arduino menggunakan kabel yang terhubung dengan port USB, bukan port serial. Fitur ini berguna karena banyak komputer yang saat ini tidak memiliki port serial.

4. Arduino adalah hardware dan software open source, software dan gambar rangkaian arduino dapat di download tanpa harus membayar ke pembuat arduino.

5. Biaya hardware cukup murah, sehingga tidak terlalu menakutkan untuk membuat kesalahan.

6. Proyek arduino ini dikembangkan dalam lingkungan pendidikan sehingga bagi pemula akan lebih cepat dan mudah mempelajarinya.

7. Memiliki begitu banyak pengguna dan komunitas di internet dapat membantu setiap kesulitan yang dihadapi.

\section{Perangkat Arduino}

Papan arduino merupakan papan microcontroller yang berukuran kecil atau dapat diartikan juga dengan suatu rangkaian berukuran kecil yang didalamnya terdapat komputer berbentuk suatu chip yang kecil.

Pada Gambar 2 dapat dilihat sebuah papan arduino dengan beberapa bagian komponen didalamnya. 


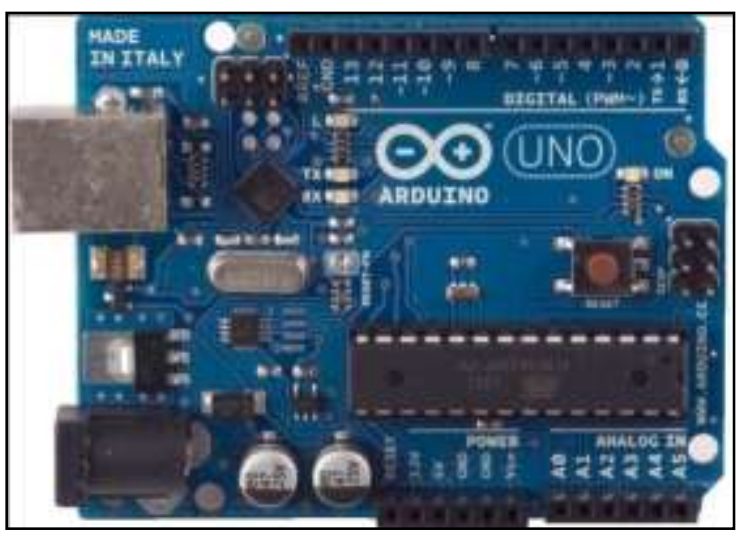

Gambar 2 Hardware Arduino Uno

Pada hardware arduino uno terdiri dari 20 pin yang meliputi:

a. 14 Pin IO digital (pin $0-13$ )

Pin digital dengan nomor 0-13 yang dapat dijadikan input atau output yang diatur dengan cara membuat programnya pada IDE.

b. 6 Pin input analog (pin 0-5)

Pin analog dengan nomor 0-5 yang dapat digunakan untuk membaca nilai input yang memiliki nilai analog dan mengubahnya ke dalam angka antara 0 dan 1023.

c. 6 Pin output analog (pin 3, 5, 6, 9, 10 dan 11)

Pin yang sebenarnya merupakan pin digital tetapi pin tersebut dapat diprogram kembali menjadi pin output analog dengan cara membuat programnya pada IDE.

\section{Software Arduino}

Software Arduino yang digunakan adalah driver dan IDE, walaupun masih ada beberapa software lain yang sangat berguna selama pengembangan arduino. IDE atau Integrated Development Environment suatu program khusus untuk suatu komputer agar dapat membuat suatu rancangan atau sketsa program untuk papan arduino. IDE Arduino merupakan software yang sangat canggih ditulis dengan menggunakan java. IDE Arduino terdiri dari:

a. Editor Program
Sebuah window yang memungkinkan pengguna menulis dan mengedit program dalam bahasa processing

b. Compiler

Sebuah modul yang mengubah kode program menjadi kode biner bagaimanapun sebuah microcontroller tidak akan bisa memahami bahasa processing.

c. Uploader

Sebuah modul yang memuat kode biner dari komputer ke dalam memory di dalam papan arduino dalam bahasa pemrograman arduino ada tiga bagian utama yaitu struktur, variabel dan fungsi :

\section{Struktur program arduino}

Kerangka program arduino sangat sederhana, yaitu terdiri atas dua blok. Blok pertama adalah void setup() dan blok kedua adalah void loop.

1) Blok Void setup ()

Berisi kode program yang hanya dijalankan sekali sesaat setelah arduino dihidupkan atau di-reset. Merupakan bagian persiapan atau instalasi program.

2) Blok void loop ()

Berisi kode program yang akan dijalankan terus menerus. Merupakan tempat untuk program utama.

Sintaks Program

Baik blok void setup loop () maupun blok function harus diberi tanda kurung kurawal buka " $\{$ " sebagai tanda awal program di blok itu dan kurung kurawal tutup "?" sebagai tanda akhir program.

\section{Variabel}

Sebuah program secara garis besar dapat didefinisikan sebagai instruksi untuk memindahkan angka dengan cara yang cerdas dengan menggunakan sebuah variabel.

\section{Fungsi}

Pada bagian ini meliputi fungsi input output digital, input output analog, advanced I/O, fungsi waktu, fungsi matematika serta fungsi komunikasi.

Pada proses Uploader dimana pada proses ini mengubah bahasa pemrograman yang nantinya dicompile oleh avr-gcc (avr-gcc compiler) yang hasilnya akan disimpan kedalam papan arduino.

Avr-gcc compiler merupakan suatu bagian penting untuk software bersifat open source. Dengan adanya avr-gcc compiler maka akan membuat bahasa pemrogaman dapat dimengerti oleh microcontroller. 
Proses terakhir ini sangat penting karena dengan adanya proses ini maka akan membuat proses pemrogaman microcontroller menjadi sangat mudah.

Berikut ini merupakan gambaran siklus yang terjadi dalam melakukan pemrogaman arduino:

1. Koneksikan papan arduino dengan komputer melalui USB port.

2. Tuliskan sketsa rancangan suatu program yang akan dimasukkan ke dalam papan arduino.

3. Upload sketsa program ke dalam papan arduino melalui kabel USB dan kemudian tunggu beberapa saat untuk melakukan restart pada papan arduino.

4. Papan arduino akan mengeksekusi rancangan sketsa program yang telah dibuat dan di-upload ke papan arduino.

\section{METODOLOGI PENELITIAN}

Metodologi penelitian yang digunakan adalah :

\section{Perancangan Sistem}

Perancangan alat penyiraman tanaman otomatis menggunakan sensor kelembaban berbasis microcontroller ATMega 328 ini menerapkan langkahlangkah sebagai berikut:

\section{Analisa Kebutuhan}

Langkah ini merupakan analisa terhadap kebutuhan sistem..

\section{Desain Sistem}

Tahapan dimana dilakukan penuangan pikiran dan perancangan sistem terhadap solusi dari permasalahan yang ada dengan menggunakan perangkat pemodelan sistem seperti diagram alir data (data flow diagram).

\section{Penulisan Kode Program}

Penulisan kode program atau coding merupakan penerjemahan design dalam bahasa yang bisa dikenali oleh komputer.

\section{Pengujian Program}

Tahapan akhir dimana dilakukan pengkajian ulang dan perbaikan terhadap alat dan coding agar menjadi lebih baik dan sempurna.

\section{PERANCANGAN SISTEM}

Perancangan alat penyiraman tanaman otomatis menggunakan sensor suhu dan kelembaban berbasis microcontroller ATMega 328. Dilakukan perancangan sistem terhadap solusi dari permasalahan yang ada dengan menggunakan perangkat pemodelan sistem seperti diagram alir data (data flow diagram).

\section{Perancangan Hardware}

Untuk merancang sistem perangkat keras yang meliputi pembuatan rangkaian hasil perancangan sistem baik rangkaian penunjang maupun rangkaian utama. Dalam hal ini terbagi dalam beberapa bagian atau blok dalam perancangan dan pembuatan alat yang dibangun. Microcontroler membaca sensor DHT 11 dan sensor Soil Moisture yang dihubungkan pada Pin 5 pada board digital dan Pin A0 pada board analog arduino uno, yang dimaksudkan untuk mendapatkan nilai suhu dan kelembaban tanah di sekitar tanaman, hal ini bertujuan untuk menjaga tingkat kelembaban tanah secara otomatis.Gambar 3 adalah block diagram yang menunjukkan hubungan antara Arduino Uno ATMega328 sebagai pusat control dengan peripheral lainnya.

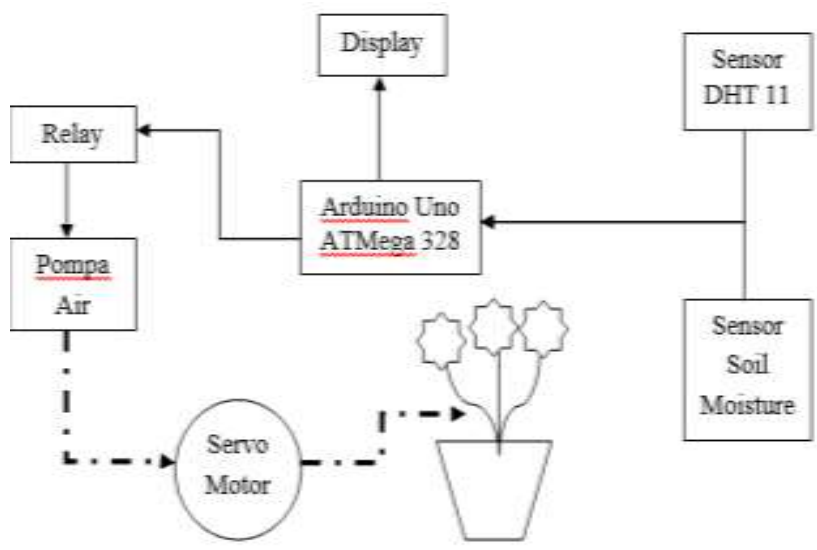

\section{Gambar 3 Block Diagram Hubungan Antara Arduino Uno} ATMega328 Sebagai Pusat Control

Dengan Peripheral Lainnya. Dalam hal ini pendeteksian di mulai dari Sensor DHT 11 yang mendeteksi Suhu dan kelembaban udara di sekitar tanaman kemudian hasil yang di dapat kemudian ditampikan ke display, kemudian untuk mendapatkan 
hasil yang lebih akurat maka di gunakan sensor Soil Moisture di sekitar tanah tanaman yang berfungsi untuk memberikan sinyal Analog mengenai nilai kelembaban tanah yang terbaca, jika sinyal digital dari DHT 11 terdeteksi $<=32^{\circ} \mathrm{C}$ dan sinyal analog dari sensor soil moisture terdeteksi $>=63 \%$ maka pompa air dan servo motor akan mati, jika sinyal digital dari DHT 11 terdeteksi $>32^{\circ} \mathrm{C}$ dan sinyal analog dari sensor soil moisture terdeteksi < $63 \%$ maka pompa air dan servo motor akan mati.

\section{Rangkaian Minimum Arduino Uno}

Pada rangkaian minimum arduino uno merupakan minimum sistem dalam bentuk skematik yang terlihat hubungan mana saja yang dihubungkan dalam serpihan tersebut. Dalam hal ini pada pin reset terhubung sebuah resistor yang dikendalikan dari sumber tegangan sebesar $5 \mathrm{~V}$ dan terhubung sebuah saklar sentuh yang digunakan untuk mengulangi kondisi semula yang terhubung ke pin reset, Gambar 4 Merupakan Rangkaian Minimum Arduino Uno

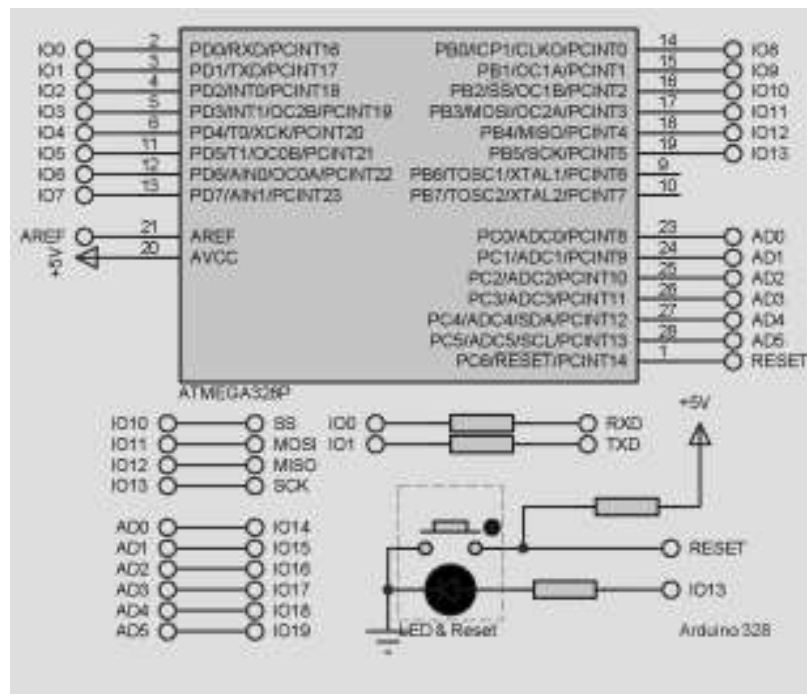

Gambar 4. Rangkaian Minimum Arduino Uno.

Pada rangkaian minimum arduino dapat di jumpai tombol reset yang ada di board arduino tersebut. Reset menandakan awal dari suatu operasi dari Microcontroler sebelum sumber tegangan menyuplai atau menuju level tegangan yang aman atau safe level. Karena pada pin reset terhubung kapasitor dan kaki yang lainnya dihubungkan ke ground. Apabila sumber tegangan telah menanjak ke keadaan threshold maka reset akan bekerja, biasanya pada saat 2V, Gambar 5 . merupakan Rangkaian Reset Pada Arduino Uno.

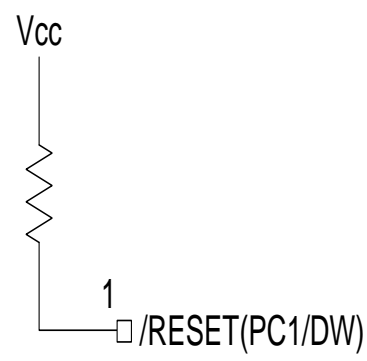

Gambar 5. Reset Pada Arduino Uno.

Untuk rangkaian internal power-on reset akan melakukan pengulangan atau reset sekitar $3 \mathrm{~ms}$ dan diikutinya penundaan waktu (delay time) sebesar $16 \mathrm{~ms}$, sebelum Microcontroler memulai eksekusi program. reset dalam rangkaian internal terdapat resistor pull-up yang digunakan sebesar 10-50 Ohm. Untuk menghasilkan clock diperlukan sebuah crystal dan ceramic resonator atau sering disebut juga capasitor ceramic. Adapun pin yang terhubung di pin yang bertuliskan XTAL1 dan XTAL2 yang digunakan sebagai input dan output, dengan adanya penguat inverting sehingga menghasilkan sebagai osilator. Yang mana osilator ini yang akan membentuk sinyal clock atau pulsa pada micro controller ATMega 328. Gambar 6 merupakan Rangkaian osilator pada Arduino Uno.

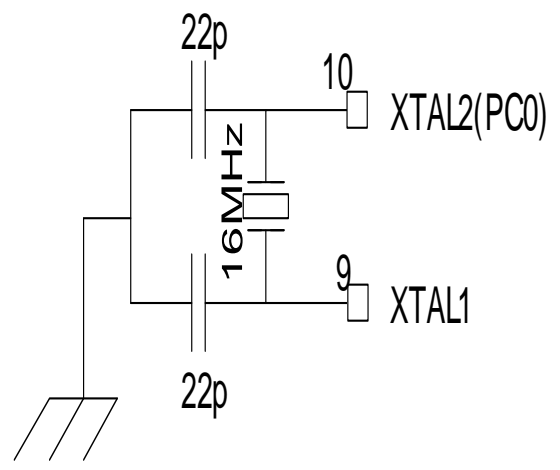

Gambar 6. Osilator Pada Arduino Uno. 
Sensor suhu dan kelembaban DHT 11 memerlukan sinyal digital yang digunakan sebagai pembaca kondisi suhu. Adapun jangkauan yang digunakan tidak boleh lebih atau kurang dari yang ditentukan dari pabrik semikonduktor. Jangkauan yang terdapat pada DHT 11 adalah $0{ }^{0} \mathrm{C}$ sampai dengan $50{ }^{\circ} \mathrm{C}$ dengan tingkat kesalahan sebesar $\pm 2{ }^{\circ} \mathrm{C}$, sedangkan jangkauan kelembabannya adalah $20-90 \%$ dengan tingkat kesalahan sebesar $\pm 5 \%$, untuk sumber tegangan (Vs) yang diperlukan adalah 5 Volt, Gambar 7 merupakan Hubungan DHT 11 ke Arduino Uno.

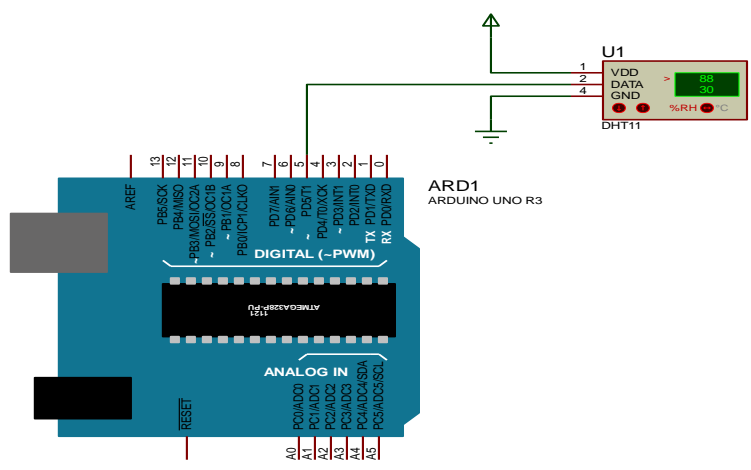

Gambar 7 Hubungan Sensor DHT 11 Ke Arduino Uno.

Cara kerja DHT 11 adalah dengan membaca kondisi suhu dan kelembaban udara di sekitar tanaman kemudian memberikan sinyal ke Microcontroller yang menerima nilai suhu dan kelembaban yang terbaca DHT 11 dan kemudian ditampilkan ke LCD. Sensor DHT 11 memiliki batas maksimum pada suhu $50^{\circ} \mathrm{C}$, pin-pin yang terhubung yaitu pin 2 pada DHT 11 dihubungkan ke Pin 5 pada board digital arduino uno , sedangkan pin 1 pada DHT 11 dihubungkan ke VCC dan Pin 3 dihubungkan ke GND.

\section{Perancangan Sensor Soil Moisture}

Sensor kelembaban Soil Moisture memerlukan sinyal analog yang digunakan sebagai pembaca kelembaban di dalam tanah., untuk sumber tegangan (Vs) yang diperlukan adalah 3-5 Volt DC, Gambar 8 merupakan Hubungan soil Moisture ke Arduino Uno.

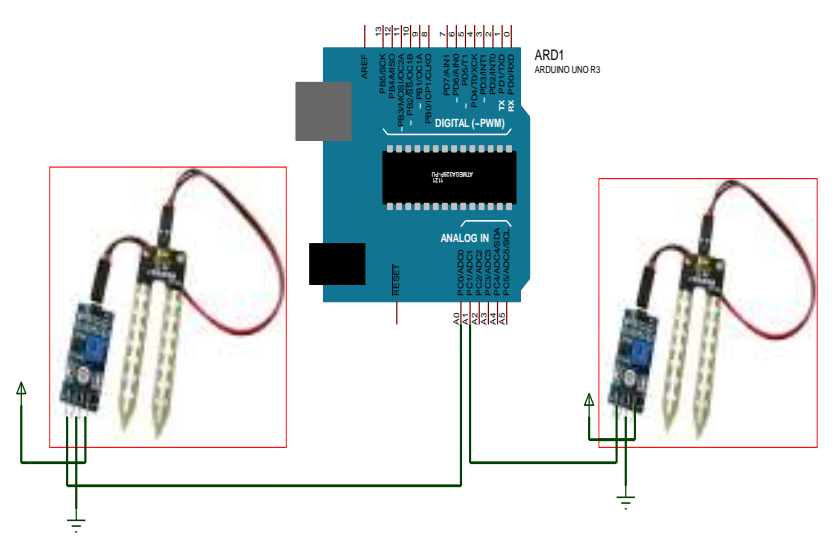

Gambar 8 Hubungan Soil Moisture Ke Arduino Uno.

Sinyal output yang diperoleh dari soil moisture tersebut merupakan sinyal analog sehingga pada hubungan pin yang terhubung ke arduino uno terkoneksi pada pin analog. Sensor ini menggunakan dua buah probe untuk melewatkan arus melalui tanah lalu membaca tingkat resistansinya untuk mendapatkan tingkat kelembaban tanah. Semakin banyak air membuat tanah lebih mudah mengalirkan arus listrik (resistansi rendah), sementara tanah kering sulit mengalirkan arus listrik (resistansi tinggi). Nilai yang terukur oleh sensor soil moisture kemudian dikirim ke arduino uno, agar arduino uno dapat membaca dan mengeksekusi nilai-nilai yang di terima maka perlu adanya hubungan antara arduino uno dengan soil moisture, Pin A0 dihubungkan pada soil moisture pertama dan A1 dihubungkan ke soil moisture kedua.

\section{Perancangan Display LCD HD44780}

LCD merupakan media display yang digunakan untuk menampilkan nilai yang terbaca dari sensor suhu dan kelembaban dimana LCD membutuhkan sumber tegangan sebesar 5 Volt D. Untuk menampilan nilai suhu dan kelembaban dengan menggunakan LCD, ada beberapa pin yang terhubung ke LCD dari arduino. Gambar 9 merupakan hubungan Pin LCD dengan Arduino. 


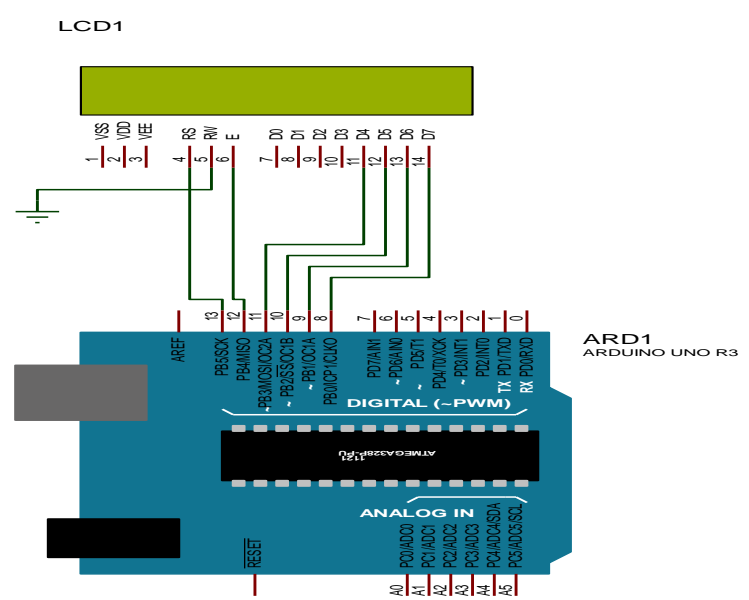

Gambar 9 Hubungan Pin LCD Dengan Arduino Uno.

Dalam hal ini, LCD yang digunakan untuk menampilkan nilai pengukuranan atau terbaca dari sensor DHT11, adapun nilai - nilai yang ditampilkan adalah nilai suhu dan kelembaban dari sekitar tanah tanaman adapun hubungan LCD dengan arduino yaitu pin Vss dihubungkan terhadap Ground begitu juga dengan pin Vee serta R/W. dalam hal ini R/W dihubungkan ke ground karena digunakan sebagai penampilan nilai ke LCD sehingga di beri sumber ke ground. Untuk pin RS terhubung ke pin 13 pada arduino dan pin E dihubungkan ke pin 12 pada arduino. Sedangkan untuk data bus dalam hal ini digunakan mode nible yang hanya digunakan 4 bit saja yaitu pada D4, D5, D6, dan D7 dimana masing - masing terhubung ke pin 11,10,9, dan 8 pada arduino.

\section{Perancangan Servo Motor}

Pengunaan servo motor adalah untuk mengatur arah pancuran air melalui selang yang dipompa dengan pompa air sesuai dengan arah yang telah ditetapkan, servo motor memerlukan sinyal digital dari arduino dimana sumber tegangan yang di perlukan adalah 5 Volt DC, Gambar 10 merupakan Hubungan Pin arduino Uno dengan Servo Motor.

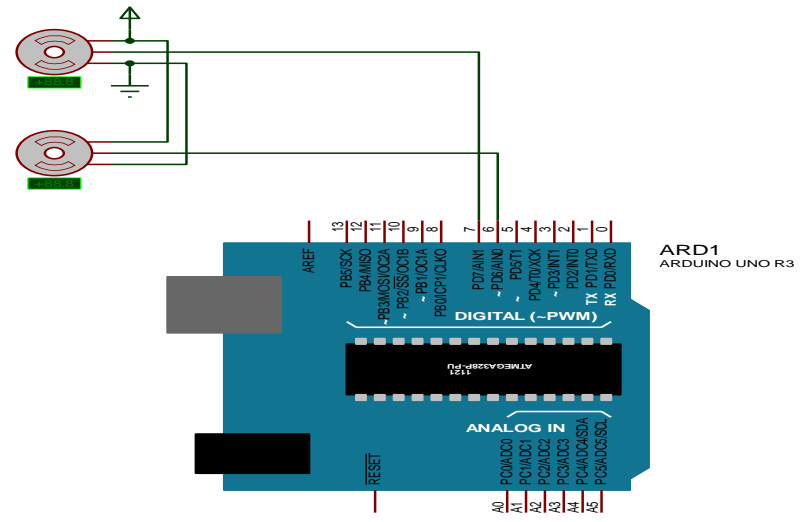

Gambar 10 Hubungan Pin Arduino Uno Dengan Servo Motor.

Dari gambar 10 dimana Pin 6 dan 7 pada board digital arduino uno di hubungkan ke bagian control servo motor (warna orange), sedangkan kabel (warna merah) dihubungkan ke VCC dan kabel (warna coklat) dihubungkan ke GND.Servo motor akan mengarah ke tanah yang apabila pembacaan dari soil moisture tersebut merujuk ke nilai kelembaban yang ditentukan. Pada servo 1 dan servo 2 digunakan untuk mengarahkan dari pembacaan soil moisture.

\section{Perancangan Relay}

Rangkaian driver relay digunakan untuk mengaktifkan pompa air, dapat juga digunakan untuk mengnonaktifkan pompa air tergantung dari sinyal masukan yang di berikan oleh microcontroller, Gambar 11 merupakan hubungan Pin relay dengan board arduino uno.

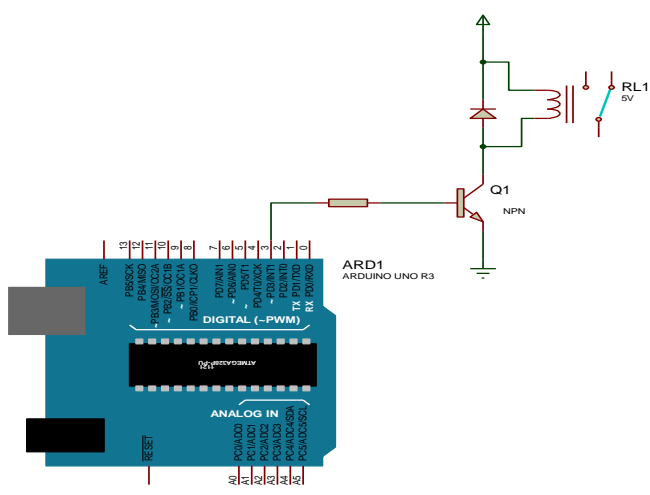

Gambar 11 hubungan Pin relay dengan board Arduino uno. 
Dari Gambar 11 relay dihubungkan pada Pin 3 pada board digital arduino uno. Dari rangkai relay menggunakan transistor dalam hal ini transistor diterapkan seperti menggunakan rangkaian switch pada transistor. Saat diberi tegangan input tinggi transistor akan mengalami saturasi maka pompa air tidak menyala dan bila diberi tegangan input rendah transistor akan tersumbat (cutoff) maka pompa air akan menyala.

\section{Perancangan Perangkat lunak}

Pada perancangan perangkat lunak yang diperlukan adalah penulisan kode. Dalam penulisan kode-kode ini akan di kompilasi dan hasil kompilasi akan menuju ke arduino board. Sebelum melakukan pemrograman dibutuhkan flowchart agar mempermudah dalam melakukan pemrograman dan selanjutnya listing program dengan menggunakan program IDE Arduino.

\section{Penyusunan Diagram Alur (Flowchart)}

Dalam hal ini pada saat dimulai (start) atau dinyalakan, sensor DHT 11 akan bekerja membaca suhu dan kelembaban udara di sekitar tanah tanaman. Dan sensor soil moisture mendeteksi kelembaban tanah tanaman. Apabila resistansi rendah maka terdeteksi kelembaban tanah tanaman $>=63 \%$ dan sinyal digital yang terdeteksi $<=32^{\circ} \mathrm{C}$ maka servo motor dan pompa air akan mati. Jika resistansi tinggi maka terdeteksi kelembaban tanah tanaman $<63 \%$ dan sinyal digital yang terdeteksi $>32^{\circ} \mathrm{C}$ maka servo motor dan pompa air akan hidup. Untuk mempermudah memahami alur program kerja dari alat ini maka dibutuhkan flowchart, Gambar 12 merupakan flow chart program Arduino IDE.

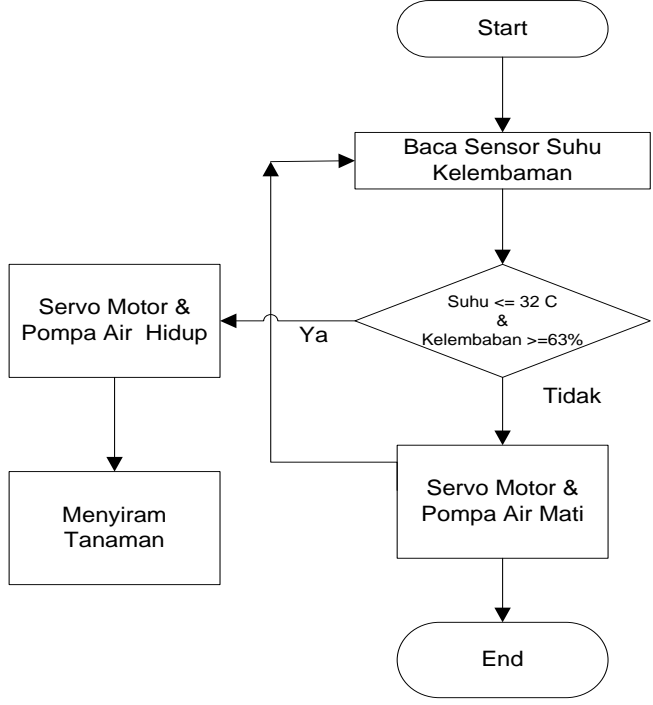

Gambar 12 Flow chart program Arduino.

\section{HASIL DAN PEMBAHASAN}

\section{Pengujian Sensor DHT 11}

Pengujian ini untuk melihat fungsi sensor DHT 11 dalam alat penyiraman tanaman otomatis mengunakan sensor kelembaban berbasis microcontroller ATMega 328. Gambar 20 dan 21 Merupakan Suhu dan Kelembaban Yang Terbaca Oleh DHT 11. Gambar 13 Suhu Dan Kelembaban Yang Terbaca DHT 11 Dibawah $32^{\circ}$ C.Gambar 14 Suhu Dan Kelembaban Yang Terbaca DHT 11 Diatas $32^{\circ} \mathrm{C}$.
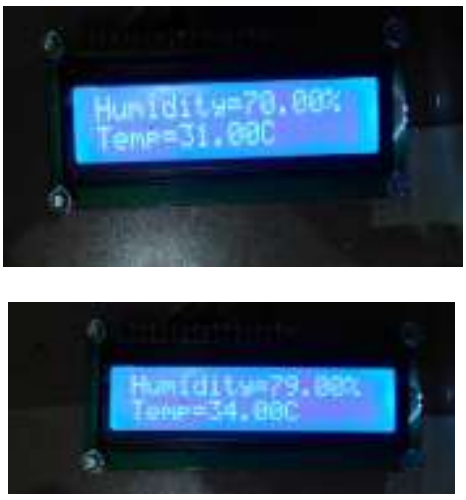

Gambar 13 menunjukan suhu dan kelembaban 
Gambar 13 dan menunjukan suhu dan kelembaban yang terbaca oleh sensor DHT 11 yang di tampilkan melalui display suhu dan kelembaban yang di baca merupakan nilai suhu dan kelembaban di sekitar tanah tanaman.

\section{Pengujian Sensor Soil Moisture}

Pengujian ini untuk melihat fungsi sensor Soil Moisture dalam alat penyiraman tanaman otomatis mengunakan sensor kelembaban berbasis microcontroller ATMega 328. Gambar 14 dan 15 merupakan kondisi tanah saat pengujian.

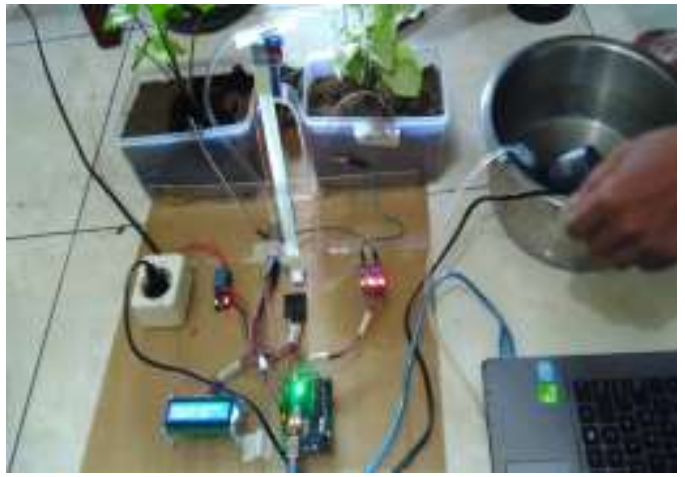

Gambar 14 Pengujian Pada Saat Kondisi Tanah Pada Salah Satu Pot Kering

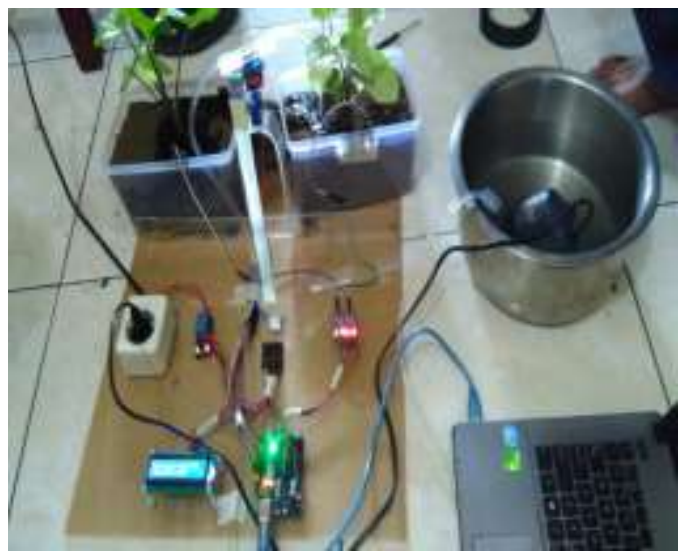

Gambar 15 Pengujian Pada Saat Kondisi Tanah Pada Kedua Pot Basah

Gambar 14 Pengujian Pada Saat Kondisi Tanah Pada Salah Satu Pot Kering. Gambar 15 Pengujian Pada Saat Kondisi Tanah Pada Kedua Pot Basah.
Gambar 15 merupakan hasil pengujian yang dilakukan salah satu probe soil moisture keadaan tanahny kering atau < 63\% dan nilai digital sensor DHT $11>32^{\circ} \mathrm{C}$ maka servo motor akan bergerak kearah pot yang kering kemudian pompa air akan hidup sampai tanah dalam pot menjadi basah.Gambar 16 merupakan hasil pengujian yang dilakukan apabila keadaan tanah pada kedua-dua pot basah maka servo motor dan pompa air akan dalam kondisi mati sampai tanah dalam pot menjadi kering kemudian pompa air dan servo motor dapat hidup.

\subsection{Pengujian Alat Secara Keseluruhan}

Pengujian alat secara keseluruhan bertujuan untuk mengetahui kerja alat penyiraman tanaman otomatis mengunakan sensor kelembaban berbasis microcontroller ATMega 328 apakah telah sesuai dengan yang diharapkan, Gambar 16 merupakan pengujian alat secara keseluruhan.

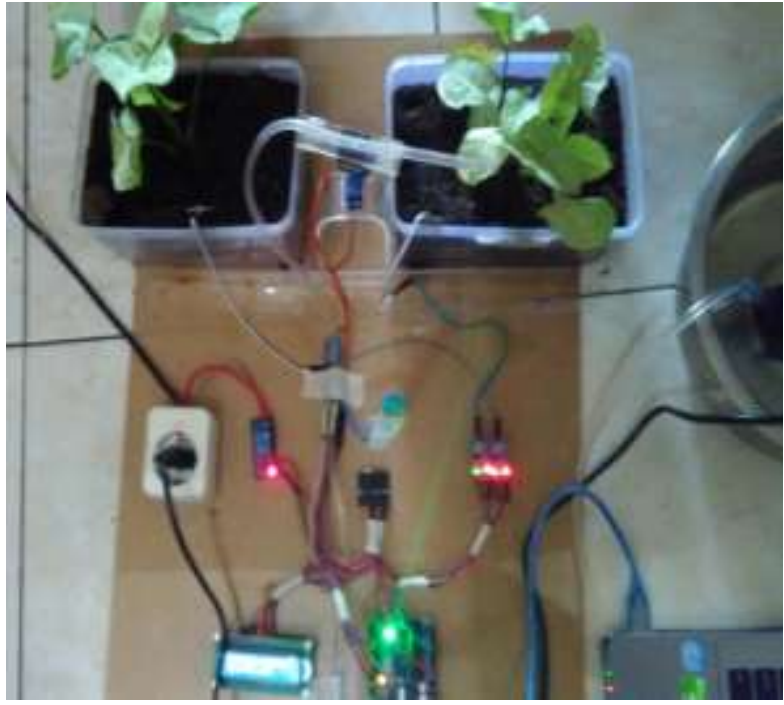

Gambar 16 Pengujian Alat Secara Keseluruhan.

Dalam hal ini sensor kelembaban Soil Moisture memberikan sinyal analog antara 0-179 ke microcontroller nilai di dapat berdasarkan kelembaban yang terbaca oleh kedua probe yang di tancapkan ke tanah tanaman nilai yang terbaca apabila di atas 120 atau di $>=63 \%$ dan nilai digital dari sensor DHT 11 terdeteksi $<32^{\circ} \mathrm{C}$ maka pompa air dan servo motor akan mati. Jika nilai analog sensor soil terdeteksi $<63 \%$ dan nilai digital dari sensor DHT 11 terdeteksi $>=32^{\circ} \mathrm{C}$ maka pompa air dan servo motor akan hidup. 
Tabel 1. Hasil Pengujian Alat Secara Keseluruhan

\begin{tabular}{|c|c|c|c|c|c|c|c|}
\hline NO & $\begin{array}{c}\text { Nilai Sinyal } \\
\text { Analog }\end{array}$ & $\begin{array}{c}\text { Nilai } \\
\text { Kelembaban } \\
(\boldsymbol{\%})\end{array}$ & $\begin{array}{c}\text { Nilai } \\
\mathbf{D H T} \mathbf{1 1} \\
\mathbf{( \mathbf { C } )}\end{array}$ & $\begin{array}{c}\text { Tanah } \\
\text { Pot 1 } \\
\mathbf{( \% )}\end{array}$ & $\begin{array}{c}\text { Tanah } \\
\text { Pot 2 } \\
(\boldsymbol{\%})\end{array}$ & $\begin{array}{c}\text { Kondisi } \\
\text { Pompa Air }\end{array}$ & $\begin{array}{c}\text { Kondisi } \\
\text { Servo Motor }\end{array}$ \\
\hline 1 & $0-17$ & $1-10 \%$ & $33^{\circ} \mathrm{C}$ & $5 \%$ & $7 \%$ & ON & ON \\
\hline 2 & $18-35$ & $11-20 \%$ & $34^{\circ} \mathrm{C}$ & $12 \%$ & $10 \%$ & ON & ON \\
\hline 3 & $36-53$ & $21-30 \%$ & $35^{\circ} \mathrm{C}$ & $23 \%$ & $21 \%$ & ON & ON \\
\hline 4 & $54-71$ & $31-40 \%$ & $31^{\circ} \mathrm{C}$ & $37 \%$ & $23 \%$ & OFF & OFF \\
\hline 5 & $72-89$ & $41-50 \%$ & $32^{\circ} \mathrm{C}$ & $43 \%$ & $33 \%$ & OFF & OFF \\
\hline 6 & $90-107$ & $51-60 \%$ & $33^{\circ} \mathrm{C}$ & $52 \%$ & $43 \%$ & ON & ON \\
\hline 7 & $108-125$ & $61-70 \%$ & $33^{\circ} \mathrm{C}$ & $65 \%$ & $55 \%$ & ON & ON \\
\hline 8 & $126-143$ & $71-80 \%$ & $35^{\circ} \mathrm{C}$ & $76 \%$ & $70 \%$ & OFF & OFF \\
\hline 9 & $144-161$ & $81-90 \%$ & $31^{\circ} \mathrm{C}$ & $87 \%$ & $75 \%$ & OFF & OFF \\
\hline 10 & $162-179$ & $91-100 \%$ & $33^{\circ} \mathrm{C}$ & $90 \%$ & $88 \%$ & OFF & OFF \\
\hline
\end{tabular}

\section{KESIMPULAN}

Setelah menyelesaikan perancangan sistem dan telah melakukan analisis terhadap alat penyiraman tanaman otomatis mengunakan sensor suhu dan kelembaban berbasis microcontroller ATMega 328, maka dapat di simpulkan sebagai berikut.

1. Sensor DHT 11 mendeteksi suhu dan kelembaban udara di sekitar tanah tanaman

2. Dengan baik dan Sensor Soil Moisture mendeteksi kelembaban di dalam tanah tanaman.

3. Servo motor dan pompa air akan hidup apabila salah satu probe sensor Soil Moisture mendeteksi kelembaban tanah tanaman di $<63 \%$ dan suhu DHT $11>=32^{\circ} \mathrm{C}$ pompa air dan servo motor akan mati apabila kedua probe sensor soil moisture mendeteksi kelembaban tanah di $>=63 \%$ dan suhu DHT $11<32^{\circ} \mathrm{C}$.

\section{DAFTAR PUSTAKA}

[1] Budiharto, Widodo, 2009, Membuat Robot Cerdas , Jakarta, Elex Media Komputindo

[2] Datasheet, AT89S51 [Online], Available: http://search.datasheetcatalog.net/key/AT89S51 [ 17
April 2011]

[3] Datasheet, Sensor Ultrasonic Distance SensorI [Online], Availble: http://www.parallax.com/28015[17 April 2013]

[4] Hartono, Slamet. 2006. Simulasi Pengisian Bak Air Menggunakan 3 Pompa Dengan Mikrokontroler AT89S51. Semarang : Universitas Semarang.

[5] InTech, Robotic Systems - Applications, Control and Programming,

2012, http://www.intechopen.com/books/robotic-systemsapplications-control-and-programming

[6] Online], Availble: http://www.parallax.com/28015[17 April 2013]

[7] Pitowarno, 2007, Robotika Desain dan Kontrol, Andi Offset Yogyakarta.

[8] Teguh Wiguna, 2005. 'Pengukuran Volume Zat Cair Menggunakan Gelombang Ultrasonik Berbasis Mikrokontroller AT89S51'[Online], Available: http://eprints.undip.ac.id/25351/1/ML2F000642.pdf [20 Mei 2011] 